\title{
The importance of domestic papers
}

\author{
Young-Kyun Kim, D.D.S., Ph.D. \\ Editor-in-Chief of JKAOMS \\ Department of Oral and Maxillofacial Surgery, Section of Dentistry, Seoul National University Bundang Hospital, Seongnam, Korea
}

From time to time, the results of Science Citation Index (Expanded) $[\mathrm{SCI}(\mathrm{E})]$ papers have been used as indicators of academic achievements and the abilities of scholars, as well as university professors. Furthermore, the importance of publication in journals with a high impact factor and the cited index is emphasized. Naturally, all scholars are trying to submit their papers to authoritative journals at the SCI(E) level, and they are submitting papers that failed to be published in domestic journals. In addition, even domestic journals are turning to English journals to be listed in SCI(E) and international journals included in the prominent index. The Journal of the Korean Association of Oral and Maxillofacial Surgery (JKAOMS) has been converted into an English journal and is currently listed in the indexes of ESCI, Scopus, PubMed, PubMed Central, and others.

As I have been writing articles in English and trying to contribute, I started to recognize many problems. Most general dentists in clinical practice and oral and maxillofacial surgeons question whether they should read papers in authoritative journals. Indeed, would articles from top authoritative journals, such as Nature and Science be useful for clinicians? Naturally, reading these journals is very necessary for scientists studying basic medicine and natural sciences, but most clinicians rarely read these journals. Rather, clinical papers such as case reports, journal reviews, and clinical studies are useful for clinicians. Papers published in native languages are useful in clinical practice because they are easy to read and

\section{Young-Kyun Kim}

Department of Oral and Maxillofacial Surgery, Section of Dentistry, Seoul National University Bundang Hospital, 82 Gumi-ro 173beon-gil, Bundanggu, Seongnam 13620, Korea

TEL: +82-31-787-7541 FAX: +82-31-787-4068

E-mail:kyk0505@snubh.org

ORCID: https://orcid.org/0000-0002-7268-3870

(c) This is an open-access article distributed under the terms of the Creative Commons Attribution Non-Commercial License (http://creativecommons.org/ licenses/by-nc/4.0/), which permits unrestricted non-commercial use, distribution, and reproduction in any medium, provided the original work is properly cited. Copyright (C) 2019 The Korean Association of Oral and Maxillofacial Surgeons. All rights reserved. understand.

In order to become an authoritative journal, it is necessary to reconsider the usefulness of papers published in English. In neighboring Japan, journals published in Japanese are popular, and many Japanese clinicians read and write articles written in their own language. Various Korean papers and magazines are published in Korea. Clinicians should not ignore domestic journals and devalue them. Rather, reading them provides a lot of useful information and can be a resource for writing a good English paper.

The JKAOMS Editorial Board must prioritize the promotion of high-quality international journals, but at the same time, it is possible to publish sister journals written in Korean because they are useful for the clinical practice of Korean oral and maxillofacial surgeons.

\section{Conflict of Interest}

No potential conflict of interest relevant to this article was reported.

How to cite this article: Kim YK. The importance of domestic papers. J Korean Assoc Oral Maxillofac Surg 2019;45:301. https:// doi.org/10.5125/jkaoms.2019.45.6.301 